Artigo Original

ORIGINAL ARTICLE

\title{
Anticorpos antimatriz extracelular e antiaorta em pacientes com arterite de Takayasu ${ }^{*}$
}

\section{Anti-extracellular matrix and anti-aorta antibodies in patients with Takayasu's arteritis}

\author{
Erika Satomi $^{(1)}$, Walcy R. Teodoro(2), Ana Paula P. Velosa ${ }^{(2)}$, Carla C. Prizon ${ }^{(3)}$, \\ Maurício Levy $\mathrm{Neto}^{(4)}$, Natalino H. Yoshinari ${ }^{(4)}$
}

\section{RESUMO}

Os componentes de matriz extracelular têm sido amplamente pesquisados nos últimos anos quanto ao seu papel na patogênese de diversas doenças difusas do tecido conjuntivo e síndromes vasculíticas. No caso da arterite de Takayasu, muito pouco se sabe sobre o assunto e são propostas teorias relacionadas com a participação da imunidade celular ou humoral para explicar a causa desta doença. Neste sentido, avaliamos a imunidade humoral nesta patologia. Objetivo: Pesquisar anticorpos contra componentes da matriz extracelular, incluindo a identificação de anticorpos anticolágeno e antiaorta. Métodos: Soros de 13 pacientes com arterite de Takayasu e de 8 pacientes normais foram utilizados para pesquisa de auto-anticorpos anticolágeno tipos I, III, IV e V e antiaorta pelo método ELISA. Resultados: Soros dos pacientes com arterite de Takayasu revelaram-se negativos para colágenos dos tipos III e IV e apenas um paciente apresentou positividade para os tipos I e V, enquanto todos os soros de pacientes com arterite de Takayasu revelaram-se negativos para anticorpos anti-aorta. Conclusões: Nossos dados demonstraram que as freqüências de anticorpos anticolágenos dos tipos I, III, IV e V não estiveram significativamente aumentadas no soro de pacientes com arterite de Takayasu, assim como os anticorpos antiextrato de aorta, sugerindo que a etiopatogenia desta vasculite esteja possivelmente relacionada com distúrbio da imunidade celular.

Palavras-chave: arterite de Takayasu, colágeno, extrato de aorta, vasculite.

\begin{abstract}
The pathogenic role of the components of extracellular matrix as causative factor of diffuse connective diseases and vasculitis has been studied extensively. The pathogenesis of Takayasu's arteritis is unknown, and many theories have been proposed to explain the etiology of this disease, involving disturbances of the humoral or cellular immune responses. Objective: To research antibodies directed to components of the extracellular matrix and aorta extract. Methods: Serum from thirteen patients with Takayasu's arteritis and from eight normal patients was tested to show the presence of autoantibodies directed to anti types I, III, IV and $V$ collagen and anti-aorta employing ELISA methodology. Results: Serum from patients with Takayasu's arteritis didn't show the presence of antibodies directed to types III and IV collagen and only one patient was positive for type $I$ and $V$ collagen. No serum was reactive with aorta extract in patients with Takayasu's arteritis as well. Conclusions: Our results didn't show the presence of antibodies directed to types I, III, IV and $V$ collagen, as well as against aorta extract, suggesting that cell immune mediated disturbance should be the mechanism involved in the etiopathogenesis of this form of vasculitis.
\end{abstract}

Keywords: Takayasu's arteritis, collagen, aorta extract, vasculitis.

\footnotetext{
* Laboratório de Investigação Médica, Disciplina de Reumatologia, Departamento de Clínica Médica da Faculdade de Medicina da Universidade de São Paulo (FMUSP), São Paulo, SP, Brasil. Suporte financeiro parcial dos Fundos Remanescentes da Sociedade Brasileira de Reumatologia. Recebido em 29/1 1/2001. Aprovado, após revisão, em 20/9/2002.

1. Quintanista de Medicina da FMUSP.

2. Biologista do LIM-17 da FMUSP.

3. Bióloga bolsista da FMUSP.

4. Médico da FMUSP.
}

Endereşo para correspondência: Natalino H. Yoshinari. Laboratório de Investigação em Reumatologia. Faculdade de Medicina da Universidade de São Paulo (FMUSP) Av. Dr. Arnaldo, 455 - 3. ${ }^{\circ}$ andar, CEP 01246-009, São Paulo, SP, Brasil. 


\section{INTRODUÇÃO}

A importância da pesquisa de anticorpos anticomponentes da matriz extracelular e antiaorta no soro de pacientes com síndromes vasculíticas é extremamente discutida com relação à sua possível participação no mecanismo etiopatogênico destas doenças.

As síndromes vasculíticas englobam diferentes modalidades clínicas e por conseqüência, diferentes mecanismos imunopatogênicos podem estar envolvidos. Classicamente, são aceitas as teorias da participação da imunidade celular ou da humoral, esta última com a presença de imunocomplexos circulantes e ativação do sistema complemento ou anticorpos antiendotélio lesando a parede $\operatorname{vascular}^{(1)}$.

Em condições normais a homeostase tecidual é mantida em estado quiescente, com crescimento celular controlado, sem expressiva remodelação da matriz extracelular. Quando este equilíbrio é rompido por diferentes mecanismos, que podem variar de inflamação a trauma físico, pode ocorrer nesses tecidos uma sucessão de eventos que levam à formação excessiva de tecido conjuntivo. Este processo de agressão da matriz extracelular ocorre geralmente após a lesão do complexo endotélio-membrana basal.

A capacidade e o tempo de regeneração do tecido conjuntivo podem variar dependendo do tipo de agressão, mas o processo de reparação é similar, ou seja, inicia-se com a migração de células sangüíneas para o local da injúria. No processo de lesão vascular, ocorre a exposição dos componentes do tecido mesenquimal, após invasão por células inflamatórias, com conseqüente reparação tecidual, ou excepcionalmente nos processos autoimunes à proliferação inadequada de componentes da matriz extracelular, deflagrando, por exemplo, os processos fibróticos, causando falência dos órgãos acometidos.

A resposta humoral contra os componentes do tecido conjuntivo e da membrana basal, tais como a laminina, a fibronectina e o colágeno, indicaria a possibilidade de que tais anticorpos poderiam desencadear e perpetuar a lesão $\operatorname{vascular}^{(, 2,3)}$. Em soros de pacientes com doenças difusas do tecido conjuntivo, foram encontrados anticorpos antilaminina e anti-colágeno, e no caso da esclerodermia, a gravidade do envolvimento pulmonar estaria associado com a presença de anticorpos anticolágenos tipos IV e V, componentes presentes na membrana basal dos $\operatorname{vasos}^{(4)}$.

A arterite de Takayasu caracteriza-se morfologicamente pela presença de infiltrado de células mononucleares e granulomas em grandes vasos, todavia, o mecanismo imuno- lógico responsável pela patogênese da vasculite é desconhecido. $\mathrm{O}$ achado de linfócitos T CD8 na parede da aorta acometida, sugere participação da imunidade celular citotóxica, enquanto a descrição prévia de anticorpos antiaorta e colágenos sugere a influência de mecanismos humorais no desencadeamento desta vasculite ${ }^{(5,6,7)}$.

Em razão destas controvérsias na literatura, estudamos a imunidade humoral nos pacientes com arterite de Takayasu, pesquisando a freqüência de anticorpos antiaorta e colágenos.

\section{MATERIAL E MÉTODOS}

\section{EXTRATO DE AORTA}

A aorta humana foi isolada e lavada com solução de PBS $\mathrm{pH} 7,3$, cortada em pequenos pedaços que foram em seguida homogeneizados em ácido acético $0,5 \mathrm{M}$ na presença de inibidores de proteases (NEM, EDTA, PMSF: concentração final $=1 \mathrm{mM})$. $\mathrm{O}$ extrato foi centrifugado a 12.000 rpm e o sobrenadante dialisado com a mesma solução durante dois dias a $4^{\circ} \mathrm{C}$, sendo a concentração protéica determinada pelo método de Lowry. O extrato de aorta foi então testado por eletroforese em gel de poliacrilamida (SDS-PAGE a 10\%) para que fossem identificadas as cadeias protéicas presentes no extrato.

\section{PESQUISA DOS ANTICORPOS ANTICOLÁGENO TIPOS I, III, IV, V E ANTIAORTA POR ELISA}

Soros de pacientes normais $(\mathrm{n}=8)$ e com arterite de Takayasu $(n=13)$, previamente conservados a $-20^{\circ} \mathrm{C}$, foram utilizados para pesquisa de auto-anticorpos pelo método imunoenzimático (ELISA). Placas de poliestireno foram sensibilizadas com $50 \mu \mathrm{L}$ de colágeno tipos I, III, IV e V (concentração $20 \mu \mathrm{g} / \mathrm{ml}$ ), ou $50 \mu \mathrm{l}$ de extrato de aorta (concentração $10 \mu \mathrm{g} / \mathrm{ml}$ ) diluídos em tampão carbonato de sódio $15 \mathrm{mM}, \mathrm{pH} 9,6$. Após 16 horas, os sítios livres foram bloqueados com $100 \mu \mathrm{l}$ de albumina bovina $1 \%$ em PBS, por uma hora à temperatura ambiente no caso de colágenos, e por 24 horas tratando-se do extrato arterial. Posteriormente, as placas foram lavadas três vezes com solução salina tamponada contendo Tween 20 à $0,05 \%$.

Em seguida, foram adicionados $50 \mu \mathrm{l}$ de soros de pacientes e de controles em triplicata, em diluições 1:50 em PBS-BSA 1\%. Após incubação de duas horas à temperatura ambiente, as placas foram lavadas com PBS-Tween20 pH 7,3 e incubadas com anti-IgG humana conjugada com peroxidase (Sigma Chem. Co) diluída 1:1000 com tampão PBS-BSA 1\%. Após a lavagem das placas, a reação foi 
revelada com o-phenilenodiamino dihidrocloreto (Sigma Chem. Co) em $10 \mathrm{ml}$ de tampão fosfato de sódio $0,2 \mathrm{M}$, pH 5,0. A reação foi interrompida pela adição de $50 \mu 1$ de ácido sulfúrico $9 \mathrm{~N}$, e sua leitura posteriormente realizada em espectrofotômetro com comprimento de onda de $492 \mathrm{~nm}$.

Considerou-se soros positivos aqueles com densidade óptica superior à média mais três desvios padrões dos oito soros controles normais.

\section{RESULTADOS}

Os soros dos pacientes com arterite de Takayasu $(n=13)$, testados para se verificar a freqüência de anticorpos anticolágeno dos tipos I, III, IV e V, revelaram-se negativos para os colágenos dos tipos III e IV, enquanto apenas um paciente apresentou sorologia positiva para os tipos I e V.

Da mesma forma, os soros dos pacientes testados para se verificar a presença de anticorpos antiextrato total de artéria humana, também revelaram-se negativos.

\section{DISCUSSÃO}

Anticorpos anticolágeno foram identificados em diversas doenças do tecido conjuntivo como: lúpus eritematoso sistêmico (LES), esclerose sistêmica progressiva, artrite reumatóide, tromboangiite obliterante, além das síndromes vasculíticas $^{(2,3,4)}$. Todavia o verdadeiro papel destes anticorpos no desencadeamento das doenças permanece obscuro.

Moreland et al.(2) compararam LES e vasculites necrosantes diversas (poliarterite nodosa, vasculite reumatóide, vasculite leucocitoclástica e granulomatose de Wegener) quanto à presença de anticorpos anticolágeno e antilaminina, obtendo: $20 \%$ de positividade para colágeno tipo I, $35 \%$ para tipo II, $55 \%$ para tipo IV, $15 \%$ para tipo V e $10 \%$ para laminina em síndromes vasculíticas; enquanto em pacientes com lúpus eritematoso sistêmico obteve $85 \%$ de positividade para colágeno tipo I, $60 \%$ para tipo II, $44 \%$ para tipo III, $85 \%$ para tipo IV, $70 \%$ para tipo V, $15 \%$ para tipo VI e $0 \%$ para laminina.

Em outro estudo, Gabrielli et al. ${ }^{(8)}$ já haviam encontrado positividade de $68 \%$ e $48 \%$ para anticorpos contra colágeno tipo IV e laminina, respectivamente, relacionando-os com a atividade da esclerodermia sistêmica, enfermidade autoimune com envolvimento vascular proeminente. Achados semelhantes foram observados por Riente et al. ${ }^{(4)}$, que associaram a presença de anticorpos anticolágeno IV e $\mathrm{V}$ com o desenvolvimento da esclerodermia. Interessante ressaltar que os colágenos dos tipos IV e V são encontrados nas membranas basais de vasos e glomérulos, e a presença de anticorpos dirigidos para estes componentes poderiam contribuir na perpetuação de processos inflamatórios.

Em nosso meio, Colônia ${ }^{(9)}$ reportou resultados semelhantes ao da literatura, ao detectar anticorpos anticolágeno tipo $\mathrm{V}$ nativo em 30 dos 64 pacientes $(46,9 \%)$ com esclerodermia sistêmica, especialmente em atividade clínica da doença. Observou freqüência menor deste anticorpo nas demais doenças do tecido conjuntivo, sendo detectado em 23 dos 96 pacientes (24\%) com diferentes enfermidades. Assim, anticorpos anticolágeno tipo V foram identificados em doença reumatóide $(12,9 \%)$, doença mista do tecido conjuntivo(18,2\%), lúpus eritematoso sistêmico $(40,6 \%)$ e em apenas 3,2\% da população controle normal.

A associação entre a positividade aos diferentes tipos de colágeno no soro de pacientes com as doenças difusas do tecido conjuntivo e síndromes vasculíticas, poderia ser de grande valia para se entender o papel patogênico destes anticorpos, assim como para compreender o padrão de acometimento clínico nestas enfermidades, inclusive permitindo a even tual correlação com a atividade de doença e prognóstico. Nesse sentido, anticorpos anticomponentes da membrana basal de vasos não seriam interpretados como epifenômenos mas participantes diretos do dano vascular.

Há diversas hipóteses que procuram justificar o papel patogênico dos anticorpos anticomponentes da matriz extracelular, no desencadeamento da autoimunidade em doenças difusas do tecido conjuntivo e síndromes vasculíticas. Destaca-se o estudo de Direskeneli et al. ${ }^{(3)}$, que sugere que a exposição de componentes do tecido conjuntivo ao sistema imune, secundária à lesão vascular, poderia ser um fator desencadeante da auto-imunidade. Esta exposição levaria à formação de anticorpos os componentes da matriz extracelular e, conseqüentemente, a resposta humoral somada à ativação do sistema complemento promoveriam a perpetuação da lesão vascular. Desta forma, estes autores sugerem que a presença de anticorpos dirigidos contra células endoteliais, componentes da matriz extracelular ou colágeno tipo IV teriam papel importante na imunopatogênese em pacientes com poliarterite nodosa e vasculite reumatóide.

Em recente tese de doutorado, Teodoro ${ }^{(10)}$ demonstrou, através de modelo experimental em animais imunizados com colágeno do tipo $\mathrm{V}$, o desenvolvimento de alterações morfológicas pulmonares muito semelhantes às observadas em lúpus eritematoso sistêmico, esclerodermia e 
algumas formas de vasculite necrosante. Entre as alterações histológicas presentes no modelo, destacam-se a destruição da camada endotelial, o aumento da espessura da parede dos pequenos vasos do tecido pulmonar, às custas do deposito subendotelial e da íntima, suboclusão arterial, e infiltrado celular leucocitário. Surpreendentemente, com relação ao estudo humoral, observou-se surgimento não apenas do anticorpo anticolágeno $\mathrm{V}$, mas também contra os tipos I e III.

O modelo experimental descrito por Teodoro enfatiza o papel patológico dos anticorpos anticolágenos, em especial contra o tipo V, no desencadeamento das complicações clínicas observadas nas doenças difusas do tecido conjuntivo, reforçando a idéia de que a presença destes anticorpos não seria apenas epifenômeno.

O presente estudo foi idealizado na tentativa de contribuir na elucidação etiopatogênica da arterite de Takayasu. Ao contrário de outras vasculites necrotizantes, não há relatos conclusivos da presença de auto-anticorpos aos componentes da matriz extracelular. Dhingra et al. ${ }^{(6,7)}$ encontraram altos níveis de gamaglobulina e imunocomplexos circulantes com significativa positividade para anticorpos antiaorta em soros de pacientes acometidos por arterite de Takayasu. Segundo estes autores, os títulos de anticorpos apresentaram-se menores após o tratamento dos extratos arteriais com a enzima colagenase, o que reforçaria o papel destes anticorpos na patogênese desta doença.

\section{REFERÊNCIAS}

1. Levy Neto M, Barbas CSV, Radu AS: Vasculites sistêmicas. In: Reumatologia para o Clínico, 59-64, Yoshinari NM, Bonfá ESD, 1. ${ }^{a}$ ed, São Paulo, Ed. Roca, 2000.

2. Moreland LW, Gay RE,Gay S: Collagen autoantibodies in patients with vaculitis and systemic lupus erythematosus. Clin Immunol Immunopathol 60:412-8, 1991.

3. Direskeneli H, Cruz DD, Khamashta MA, Hughes GRV: Autoantibodies against endothelial cells, extracellular matrix, and human colagen type IV in patients with systemic vasculitis. Clin Immunol Immunopathol 70:206-10, 1994.

4. Riente L, Marchini B, Dolcher MP, Puccetti A, Bombardieri S, Migliorini P: Anti-collagen antibodies in systemic sclerosis and in primary Raynaud's phenomenon. Clin Exp Immunol 102(2): $354-$ 9, 1995

5. Baltazares M, Mendoza F, Dábague J, Reyes PA: Anti-aorta antibodies and Takayasu arteritis. Int J Cardiol 66 (S1): S183-7, 1998.

6. Dhingra R, Talwar KK, Chopra P, Kulmar R: An enzyme linked immunosorbent assay for detection of anti-aorta antibodies in Takayasu's arteritis patients. Int J Cardiol 40: 237-342, 1993.
Por outro lado, Baltazares et al. ${ }^{(5)}$ não encontraram positividade para anticorpos anticomponentes da matriz extracelular utilizando os mesmos métodos laboratoriais, e propuseram que na patogênese da doença, a imunidade celular teria papel mais relevante, em conseqüência dos achados de linfócitos CD8 na parede arterial e ligação dos mesmos aos seus receptores específicos.

Os resultados do presente trabalho reforçam a hipótese da participação da imunidade celular no desencadeamento da arterite de Takayasu, pois não foram detectados anticorpos anticolágenos I, II, IV e V, tampouco antiaorta em nossos pacientes. Neste sentido, Imiela et al. ${ }^{(11)} \mathrm{de}-$ monstraram aumento da adesividade de linfócitos $\mathrm{T}$ circulantes ao endotélio e às proteínas da matriz extracelular, em particular fibronectina e colágeno do tipo IV, hiperadesividade reversível com o tratamento da doença. Górski et al. ${ }^{(12)}$ encontraram resultados semelhantes, demonstrando o aumento de adesividade de linfócitos $\mathrm{T}$ a diferentes componentes de matriz extracelular, principalmente colágeno tipo IV.

Portanto, o processo imunopatológico na arterite de Takayasu parece estar relacionado com um evento mediado pela imunidade celular, dependente de células citotóxicas, possivelmente sensibilizadas aos diferentes componentes da matriz extracelular, modulando e direcionando a intensidade e o padrão de acometimento dos vasos nesta enfermidade.

7. Dhingra R, Chopra P, Talwar KK, Kulmar R: Enzyme-linked immunosorbent assay and immunoblot study in Takayasu's arteritis patients. Indian heart J 50: 428-32, 1998.

8. Gabrielli A, Montroni M, Rupollis S, Caniglia ML, Delustro F, Danieli G: A retrospective study of antibodies against basement membrane antigens (type IV collagen and laminin) in Raynaud's phenomenon. Arthritis Reum 31(11): 1432-36, 1988.

9. Colonia AMN: Determinação do anticorpo anti-colágeno tipo V na esclerodermia sistêmica. São Paulo, 1997. Dissertação (mestrado). FMUSP.

10. Teodoro WR: Imunogenicidade ao colágeno do tipo V em coelhos: um novo modelo experimental para estudo da patogênese da vasculite de hipersensibilidade autoimune. São Paulo, 2001. Tese de doutorado. FMUSP.

11. Imiela J, Górski A, Dybowska B, Malecki R, Nosarzewski J: Disturbances of $\mathrm{T}$-cell interactions with endothelium and the extracellular matrix proteins in a patient with Takayasu arteritis. J Int Med 235: 609-12, 1994.

12. Górski A, Piekarczyk J, Skurzak H, et al: Abnormalities in T cell interactions with extracellular matrix proteins in a patient with Wegener's granulomatosis. Clin Immunol Immunopathol 69:149-54, 1993. 